DOI: https://doi.org/10.47405/mjssh.v6i9.1055

\begin{tabular}{|c|c|}
\hline 4 & Malaysian Journal of Social Sciences and Humanities (MJSSH) \\
\hline $\begin{array}{l}\text { Malaysian Juoural of } \\
\text { Social ccciecces and }\end{array}$ & Volume 6, Issue 9, September 2021 \\
\hline (MJ-sSH) & e-ISSN : 2504-8562 \\
\hline & $\begin{array}{l}\text { Journal home page: } \\
\text { www.msocialsciences.com }\end{array}$ \\
\hline
\end{tabular}

\title{
Globalization as a Factor for Language Endangerment: Nigerian Indigenous Languages in Focus
}

\author{
Sale Maikanti' ${ }^{1}$, Austin Chukwu' ${ }^{1}$ Moses Gideon Odibah ${ }^{2}$, Moses Valentina Ogu² \\ ${ }^{1}$ Department of Hausa, Department of Igbo, Adeyemi College of Education, Ondo, Nigeria \\ 2Department of General Studies Education, Kogi State College of Education (Technical), Kabba, Nigeria \\ Correspondence: Sale Maikanti (maikanti86@gmail.com)
}

\begin{abstract}
Globalization can be viewed from economic, cultural and socio-political perspectives including information and communication technology (ICT). In view of this, it is seen as the increasing empowerment of western cultural values including language, philosophy and world view. In many African countries Nigeria inclusive, English language which is the language of colonization is gradually becoming a global language due to its influence and subsequent adoption as the official language by many African nations which are largely multi-cultural and multilingual under the British colony. This trend has not only relegated the status of Nigerian Indigenous languages to the background but has also threatened their existence in Nigeria which accommodates over 500 native languages. If this trend is left unchecked, the ill-wind of globalization will gradually sweep the native languages including the so-called major ones (Hausa, Igbo and Yoruba) out of existence particularly in Nigeria. This paper discusses globalization as one of the major factors for language endangerment with respect to Nigeria as a nation, with a view to proffering possible solutions capable of sustaining and empowering the nation's socio-cultural and economic stability.
\end{abstract}

Keywords: globalization, empowerment, languages, endangerment, multilingual

\section{Introduction}

Africa is said to be the continent with the world's most linguistically diverse. It is established that the central African Republic with a population of about 3 million has 18 distinct language groups; Cameroon - 279 languages; DRC 221 languages; Chad 127 languages; Tanzania 131 languages, Zimbabwe 16 languages and Nigeria, a whopping 400 languages. As predicted by many scholars that, as many as 60 to $90 \%$ of the world's languages, about 6,900 of them are at risk of extinction within the next 100 years (Romain 2007, p. 115). Tsiko (2004) equally raises an alarm over UNESCO's report that between 500 to 600 of African's languages are declining out of which 250 languages are under threat and gradually disappearing forever. The UNESCO'S World Atlas of the World's Languages in Danger of Disappearing (2001) estimates that 50\% of languages may be in various degrees of endangerment. Igbo and many other minority languages in Nigeria are at the risk of possible extinction in the next 50-100 years if nothing serious is done to revive them.

However, with the continued expansion and patronizing of "international languages" such as English and French, the credibility of indigenous language programs will no doubt become weak and highly vulnerable (Odugu, 2011). This is in addition to the negative effect of globalization threatening the 
existence and survival of indigenous languages. Tarugarira (2009) argues that, language endangerment is not peculiar to Nigeria's indigenous languages alone; it cuts across other African nations and the world at large. According to him, Kenya's indigenous languages appear to be fading the worst with sixteen languages on death list. The country (Kenya) by far surpasses their neighbour Uganda where six languages are under threat and Tanzania with eight languages about to disappear (p. 139). It is estimated that a language becomes extinct roughly every two weeks.

According to Joseph, Johanna, Neil and Ilse (2003), competition between Afrikaans and English is itself reminiscent of that which occurred between various European national languages and English in North America, as they 'collided' within the same socio-economic structure and lost to English language (p. 8). The evidence for the concern languages under threat can be seen in the steady stream of works available on sociolinguistic issue (Fishman, 2001; Agwuele, 2010; Tarugarira, 2009; Ode, 2015 \& Dega, 2015). Expressing his concern about language endangerment and its apparent causes, Dega posits that it is estimated that mostly in some regions across the world; about $90 \%$ of the languages may be replaced by dominant languages at the end of the $21^{\text {st }}$ century.

One of the major reasons behind this prediction is that, fewer than $4 \%$ of the world's languages have official status in their respective countries, where they are spoken. Most of them are unwritten, and only restricted to local community and homes where they are spoken by small group of people. Relatively, other factors responsible for language endangerment include attitudinal problems towards indigenous languages, especially by the elites who neither speak their native languages nor allow their children to learn them at home. Romain (2007, p. 121) adds, "languages are at risk when they are no longer transmitted naturally to children in the home by parents or other caretakers". In addition, other issues such as unpredicted human migration due to war/insurgency (boko haram), famine, and disaster are other factors that are capable of dislodging people from their settlements.

The fact that, devastating ferocious diseases, habitat displacement as well as impact of globalization leading to language and cultural extinction, this paper examines Nigerian indigenous languages with a view to ascertain the impact of globalization. Possible relevant solutions capable of changing the situation for the better towards language development and national cohesion have been proffered.

\section{Concept of Globalization}

Globalisation is a very complex phenomenon that has been defined in various ways. According to Wikipedia, it is the process of international integration arising from the interchange of world views, products, ideas and other aspects of culture. Accordingly, Adedimeji (2009) sees it as the increasing empowerment of western cultural values, including language, philosophy and worldview and the predominance of escalation in the mobility of labour, information and services. He further adds that, like all revolutions, globalization appears to threaten the economic, socio-cultural, linguistic, educational and political independence of all people in the World such that the question of survival in the global World is central to developing nations among which Nigeria ranks high.

This clearly indicates that globalization is a phenomenon that is transforming every aspect of human life and national endeavour including their language and cultural values. Thus, it can be seen as a social process characterized by the existence of global economic, political, cultural, linguistic and environmental interconnections and flows that make the many of the currently existing borders and boundaries irrelevant. Globalization therefore, enables languages and their cultures to spread and dominate other minority languages on a global scale.

Although, many scholars have emphasized more on economic impact of globalization, where it is seen as a course of unification of global patterns of production and consumption. Kubota (2001) views globalization from sociolinguistic point and says, the tremendous impact of globalization on the World has engendered the entrenchment of the Anglo-American culture with the English language emerging as a global language spoken by more than two billion people across the world. This line of though may hinge on the fact that, language is the lifeline of globalization. Without language, there would be no 
globalization and by extension, there would be no World languages as well. In fact, Fishman (2001) describes the linguistic situation of English as both a consequence and a contributor to globalization. Apart from other attractive attributes, English is highly rated in terms of prestige, status and functionality (p. 38).

As the Nigerian linguistic space is not an exception to this emerging reality, Awonusi (2006) notes that one of the fundamental ways through which globalization affects the nation today is at the level of cultural and linguistic identity. In this regard, the linguistic situation in Nigeria is that of dominant and dominated languages at different degrees and stages. Dega (2015) reveals that English has occupied a hegemonic status as it dominates the three major languages which in turn dominate the layers of the vast minority languages in the country through its official, instrumental and integrative functions. The hegemonic role of English language in Nigeria has reduced the status of local languages to the subsidiary level hence, local languages are seen and treated as "second class languages". Consequent upon this, Dega (2015) further laments that:

It is fashionable now in Nigeria for parents to relate to their children in the home, in English, believing that it is the language that will be of a greater economic benefit to them, even when both parents come from the same ethnic group. The result therefore is that the local languages in Nigeria are threatened by the hegemony of English (p. 18).

Moreover, the role of English has further increased by the desire to participate effectively in the gains of globalization with its technological know-how, the internet and integrated world economy, the computer and cyber age. However, not all scholars believe that the indigenous languages can only play subsidiary roles or second fiddle in the current global trend. For instance, in an attempt to create awareness on the dangers inherent in neglecting the indigenous languages and transferring their crucial roles to English, Owolabi (2006) remarks that:

The rapid and genuine technological, social and economic empowerment of the vast majority of Nigerians so as to enable them to utilize scientific and technological knowledge in creating wealth, self-reliance and equality of life and to contribute meaningfully to national development can only be possible through the media of their own native languages but not through imposed foreign languages such as English and French.

It is therefore, sufficient to note that the current era of globalization appears on the surface to be antithetical to the survival of indigenous languages but it behoves every linguistic nationality as observed by Owolabi to preserve its cultural and linguistic heritage so as not to lose its past and present, and by extension, its future.

\section{Language Endangerment and its Implications}

Agwuele (2010) states that, language endangerment is a socio-linguistic term used to describe languages that are in the process of being eclipsed in their cultural domain by other languages. Thus, an endangered language is one likely to become extinct in the near future. Part of UNESCO Red Book's classification of language endangerment include those that are "extinct" and "nearly extinct". These refer to languages that have completely or nearly gone out of use or for which there are either only a few or no living speakers. However, the criteria for defining "seriously endangered", "endangered" or "potentially endangered" languages vis-a-vis the "safe" or the "non-endangered" seem to be more nebulous (Azuonye, 2002 p. 41).

Accordingly, there are many reasons why a language might become endangered or extinct. One of such factors is language contact. In this case, when two or more languages come into contact with one another for one reason or the other, the possibility a major language dominating the weaker ones is 
there. The report of UNESCO reveals that as many as $50 \%$ of the world's languages are no longer being learned by new generations of speakers, thus weakening and endangering their existence.

Relatively, in the organisation's compilation of dying languages in the world in a book titled: 'Red Book on Endangered Languages', it is shown that more than 36 Nigerian languages are gradually dying. It further adds that the world could be dominated by very few languages in the nearest future. Even one of the major Nigerian languages, Igbo is among those recently predicted by UNESCO Advisory Committee on languages that may be heading for extinction if nothing is done to curtail the situation and ensure their survival and safety.

The implication of language endangerment manifests more on the culture of the speech community which usually suffers the same fate with the language. This is because language and culture share mutual relationship and go hand in hand as a loss language is a loss culture and consequently, loss of knowledge. In essence, the loss of language also causes the loss of other culturally significant practices that are dependent on the language. For instance oral histories and traditions are lost if no one can speak the language any more. Likewise, traditional songs, poetry and other verbal artistic forms are also lost with the language.

As a matter of fact, language loss, which can occur when a language is extremely endangered beyond redemption, has a significant implication on both the collective and the individual identities of the speech community. In Africa, more especially Nigeria and Ghana that passed through British colony, the so-called elites cherish western cultures much more that than their traditions. They discourage their children from speaking their mother-tongues (MT) or practice their traditional cultures. Rather, they encourage them to speak more of English language and dress like westerners.

It is pertinent to note that in Nigeria, the Federal Government has realised the enormous importance of language as a tool for social interaction, national unity and development. Hence, the National Policy on Education (NPE) was introduced in 1977 which was revised in 1981, 1998 and 2004 as a way of ensuring the sustenance of the various languages in the country, particularly the major ones and prevent them from being endangered. No doubt this constitutional provision on language was applauded by all and sundry, though the implementation is not encouraging.

Due to agitations especially by the speakers of other minority languages who felt they are being shortchanged because these policies did not extend to then to get the same national recognition like that of Hausa, Yorùbá and Igbo and coupled with the poor implementation of the language policy, made the entire process ineffective and thereby failing to ensure the survival of the languages. Moreover, as an alternative or rather complementary measure to address the issue of language endangerment in the nation, Bamgbose (2016), Adegbija (1994) have advocated what is referred to as 'linguistic social responsibility'. It is a call for linguists to ensure usage of mother tongues in extended domains. In doing that, it can be construed as a strategy for mitigating language endangerment in our local environment.

\section{Globalization and Language Endangerment in Nigeria}

Languages of the world perform communicative role and every group aspires to promote its language no matter how small or big. However, language is a veritable tool for globalization which is more or less a phenomenon that has strong desire to use a common language (English) in its processes of integrating social, economic, cultural and political life of the people in the world using a common language.

In Nigeria, due to the great importance attached to English language which serves as official language and the lingua franca, as well as its relevance in global communication process, most of the local languages have been relegated to the background. Ndimele (2005) is of the opinion that the fortunes of a language are tied to the fortunes of its speakers (125). Hence, when a people become important their language also become important, and people for whom the language is not their mother tongue will 
struggle to learn it for obvious reasons. This is applicable to the attitude of Nigerians toward English and the indigenous languages. In this regard, Babajide (2001) maintains that:

\begin{abstract}
as far and language learning and acquisition is concerned, especially in Nigeria where there is pronounced linguistic multiplicity or plurality of languages such that adjacent communities use mutually unintelligible languages, people tend to be more favourably and positively disposed to using and tolerating a language that has a considerable national and international coverage of users; a metropolitan or consumption status; a considerable numerical strength and some measure of economic and political power and a sufficiently reliable codified form (35).
\end{abstract}

From all indications, there is no gain saying that the above attributes favour English language and neither any of the Nigerian indigenous languages. Consequently, in Nigeria today, English is used in most situations: at home, office, market, school, churches and in social gatherings for all imaginable communications or interactions: formal, informal, cordial, casual and so on.

On the other hand, the attitude of the Nigerian elite to indigenous languages, according to Bamgbose (2016) reflects that they are plagued by linguistic imperialism. This is an attitude that sees it as normal towards continued use of European languages in all advanced sectors of human life (p. 26). According to Oyetade (2001), this is attributable to the inferior status accorded the indigenous language on the school curriculum (p. 47).

Babajide (2001) equally maintains that people's attitudes towards the local languages are bound to be negative due to their shortcomings such as: their restriction in use to a few native speakers; being mere vernaculars, not yet codified; associated only with rural and their irrelevance to the socio-economic and political needs of the people (p. 35). While these undesirable attributes are no longer tenable to some of the indigenous languages, especially the major ones, such cannot be said of the numerous others. It is sufficient to note that all these attitudinal problems associated with the indigenous languages since the introduction and subsequent adoption of English as official languages and the nation's lingua franca has contributed in no small measure in endangering the indigenous languages particularly in Nigeria and African continent as a whole.

\title{
Conclusion and Recommendations
}

From the discussion so far, it can be deduced that globalization is a multi-faceted phenomenon that touches every aspect of human life such as economic, social, political, commercial, information, communication, technology as well as linguistics. It is an agent of transformation and its impact both negative and positive are being felt across the globe. This discussion dwelled more on the linguistic aspect of globalization and specifically on the dominance of English language, which is regarded as a global language. In essence, the domination of Nigerian indigenous languages in Nigeria by English language has therefore endangered their lives and is consequently pushing them into extinction.

The paper also looked at the implication of language loss and by extension, loss of the peoples' cultural values and identity which could be very devastating. Furthermore, the paper therefore, discussed the impact of globalization on language endangerment at both local and international levels. While the study projected English language to be a global language, the indigenous languages are being relegated to the background and this makes them non-attractive even to the intuitive speakers of these languages. The question now is, must the indigenous languages in Nigeria be allowed to perish in the face of globalization before something could be done? If, the answer is no, then how can they be revived, sustained and empowered to cope with the future challenges in a globalized society? To address this situation, the paper made the following recommendations:

i. Adequate effort should be made to ensure that indigenous languages are used in extended domains, as suggested by Bamgbose (2016).

ii. There is the need for attitudinal change in favour of the native languages to foster their status, usage and relevance in the society. 
iii. There is the need to review the National Language Policy so as to adequately promote the teaching and learning of indigenous languages in schools across the nation, as well as to ensure its proper implementation at all levels.

iv. The constitutional provisions on indigenous languages, which include their usage from time to time in the law making as well as judicial processes should also be properly implemented.

v. Again, credit pass in any of the indigenous languages in school certificate examination should be made a pre-requisite for admission into higher institution more especially in arts related courses. This will strongly arouse the interest of the youth towards the study of the languages.

vi. The Nigerian languages graduates should as well be employed in some strategic government offices to further motivate the younger generations.

Finally, certain aspect of globalization like the information and communication technology (ICT) should be harnessed and channelled towards the sustenance and development of these local languages specifically the internet and computers which could be used to source, store and disseminate information pertaining to these languages. There are language websites that dwells on language research and documentations as well as teaching and learning of other languages. If the above recommendations can be properly studied and considered for implementation, it will go a long way in reviving the indigenous languages and making them much more relevant in the society for the betterment of humanity.

\section{References}

Adedimeji, M. A. (2009). Globalization and the survival of the Nigerian cultural linguistic heritage. The American paradigm. Ilorin: University of Ilorin.

Adegbija, E. (1994). The context of language planning in Africa: An illustration with Nigeria. In M. Putz (ed.) Language Contact and Language Conflict. Amsterdam. Philadelphia Company.

Agwuele, O. (2010). Globalization, dying languages and the futility of saving them. Mode of access: http://www.inst.at/trans/17Nr/1-3/1-3_agwuele17.htm (дата обращения-03.03. 2020).

Awonusi, V. O. (2006). Language as an instrument of African identity in the age of globalization. Science and Humanities Journal, 1(1), 25-47.

Azuonye, C. (2002). Igbo as an endangered language. In presented at the Seminar on the Problems and Methodology for the Preservation of the Igbo Language, at the Nicon-Noga Hotel, Abuja, under the Auspices of the World Bank Igbo Language Fund, 2002. 17.

Babajide, A. O. (2001). Language attitude patterns of Nigerians. In H. S. Igboanusi (ed.) Language Attitude and Language Conflict in West Africa, (pp. 1-13), Ibadan. Enicrownfit Pub.

Bamgbose, A. (2016). Language provisions of Nigeria's National Policy of Education: Declaration without implementation. A lead paper presented at NINLAN National conference Aba, March $7^{\text {th }}-11^{\text {th }}$.

Dega, A. (2015). Language endangerment: Globalization and the fate of minority languages in Nigeria. In O. M. Ndimele (ed.) Nigerian Linguists Festschrift Series, (pp. 12-28), Port Harcourt M \& J. Grand Orbit Communication LTD.

Federal Republic of Nigeria (1977). National policy on education. Lagos, Nigeria: Ministry of Education.

Federal Republic of Nigeria (1981). National policy on education. Lagos, Nigeria: Ministry of Education.

Federal Republic of Nigeria (1998). National policy on education. Abuja, Nigeria: Ministry of Education.

Federal Republic of Nigeria (2004). National policy on education. Abuja, Nigeria: Ministry of Education.

Fishman, J. A. (2001). Why is it so hard to save a threatened language? (A perspective on the cases that follow). In Can Threatened Languages be saved? (pp. 1-22). Multilingual Matters.

Joseph, B., Jonna, D., Neil, J. \& Ilse, L. (2003). When languages collides: Perspectives on language conflict, language competition, and language co-existence. Columbus: Ohio University Press. 
Kubota, R. (2001). Teaching world Englishes to native speakers of English in the USA. World Englishes, 20(1), 47-64.

Ndimele, O. M. (2005). ICT, globalization and the future of human language. In O. M. Ndimele (ed.) Globalization and the Study of Languages in Africa, (pp. 1-18). Port Harcourt: Grand Orbit and Emhai Press.

Ode, O. O. (2015). Threats to mother tongues in Nigeria: Strategies for revitalization. In O. M. Ndimele (ed.) The Linguists Festschrift Series, (pp. 29-38). Port Harcourt: Grand Orbit and Emhai Press.

Odugu D. I. (2011). Education language policy process in multilingual society: Global visions and local agendas in India, Nigeria and UNESCO. Unpublished PhD thesis, Loyola University Chicago, USA.

Oyetade, S. O. (2001). Attitude to foreign languages and indigenous language use in Nigeria. In H. S. Igboanusi (ed.) Language Attitude and Language Conflict in West Africa, (pp. 14-29). Ibadan: Enicrownfit.

Owolabi, K. (2006). Nigeria's native language modernization in specialized domains for National development: A linguist's approach. An Inaugural Lecture, University of Ibadan.

Romain, S. (2007). Preserving endangered languages. Language and Linguistics Compass, Journal Compilation, (1)1-2, 115-132.

Tarugarira, G. (2009). Rethinking the developmental nexus between indigenous languages and capacity building in science and technology: A therapeutic approach to Africa's perennial development problems. Journal of Sustainable Development in Africa, 10(4), 192-199.

Tsiko, S. (2004). Minority languages face extinction. The Herald, 17(05), 23-29.

UNESCO (2001). World Atlas of the world's languages in danger of disappearing. Paris: UNESCO. 